\title{
PRÁTICAS CONTEMPORÂNEAS DE MARKETING EM ESCRITÓRIOS DE CONTABILIDADE DE SANTA CATARINA
}

Lenoir Hoeckesfeld ${ }^{1}$

Jackson Cittadin ${ }^{2}$

Aléssio Sarquis ${ }^{3}$

Fernando César Lenzi ${ }^{1}$

\footnotetext{
${ }^{1}$ Universidade do Vale do Itajaí

${ }^{2}$ Núcleo de Ensino Superior em Tecnologia de Processos Gerenciais / Faculdade / SENAC-SC

${ }^{3}$ Programa de Pós-Graduação em Administração / Universidade do Sul de Santa Catarina (UNISUL)
} 


\section{PRÁTICAS CONTEMPORÂNEAS DE MARKETING EM ESCRITÓRIOS DE CONTABILIDADE DE SANTA CATARINA}

\section{Resumo:}

Práticas contemporâneas de marketing focalizam o processo de relacionamento com clientes. O estudo analisou práticas contemporâneas de marketing em empresas de Contabilidade, na perspectiva relacional, segundo o modelo de Coviello, Brodie e Munro (1997). Trata-se de estudo descritivo, survey, com questionário autoadministrado e participação de 58 empresas; os dados foram analisados através de técnicas de estatística descritiva. Resultados revelaram que a participação das empresas deste setor em ações de marketing ainda deve ser estimulada. Gestores deste segmento ainda não percebem a importância de estudar, entender e atender os consumidores de maneira diferente, buscando por meio de estratégias de marketing obter vantagem competitiva sustentável; as métricas de desempenho mais utilizadas são satisfação, retenção e conquista de novos clientes. O estudo contribuiu para ampliar conhecimento sobre o tema, ao examinar as diferenças estatísticas e apresentar contribuições gerenciais aos profissionais de Contabilidade.

Palavras-chave: Práticas Contemporâneas de Marketing. Marketing de Relacionamento. Serviços Profissionais. Contabilidade.

\section{Introdução}

O conceito de práticas contemporâneas de marketing compreende aspectos (estratégias, ações) que transcendem ao composto de marketing tradicional (conhecido como 4P's) e inclui: gestão do relacionamento com clientes, marketing em rede, inovação em marketing, marketing de experiências, marketing digital e marketing centrado no ser humano (O'DWYER; GILMORE; CARSON, 2009). As práticas contemporâneas de marketing variam em função do nível de interação da empresa com os clientes, podendo variar de contato distante e impessoal com consumidores passivos (foco na transação) até o desenvolvimento de relações com proximidade e de maneira contínua e individualizada (COVIELLO; BRODIE; MUNRO, 1997).

O setor de contabilidade é caracterizado como serviço profissional. Estes, são serviços considerados técnicos e especializados, onde o cliente busca obter no fornecedor o conhecimento que não dispõe, como em serviços de engenharias, advocacia, consultorias, contábeis e outros (SWEENEY; SOUTAR; MCCOLL-KENNEDY, 2011; PATTERSON, 2016). Neles, o processo de execução é fundamentado nas pessoas (quem detêm o conhecimento desejado), sendo os bens e equipamentos utilizados como ferramentas de apoio (REID, 2008) serviços executados por indivíduos qualificados, independentes e focados na resolução de problemas do cliente (PATTERSON, 2016).
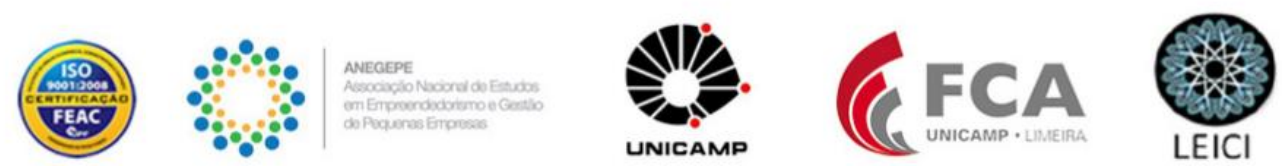
No Brasil, a participação do setor de serviços é elevada e representa cerca de $67 \%$ do Produto Interno Bruto (PEREIRA; BASTOS; PEROBELLI, 2013). De acordo com o Instituto Brasileiro de Geografia e Estatística (IBGE, 2017), o setor de serviços no país é bastante heterogêneo quanto ao porte das empresas, remuneração dos funcionários e intensidade de uso da tecnologia; necessita de melhorias nas ferramentas de gestão, no desenvolvimento de competências e habilidades, e obter ganhos em competitividade. De acordo com o Sebrae (2017), as Micro e Pequenas Empresas já são as principais geradoras de riqueza no comércio no Brasil (53,4\% do PIB deste setor, em 2015). No PIB da indústria, a participação das micro e pequenas $(22,5 \%)$ se aproxima das médias empresas $(24,5 \%)$. E no setor de serviços (objeto deste estudo), mais de um terço da produção PIB (36,3\%) têm origem nos pequenos negócios.

Os estudos bibliométricos de Ensslin et al. (2015) e Sarquis et al. (2016) sobre práticas de marketing para pequenas empresas analisaram um portfólio de artigos e referências publicados em 10 anos (2005 a 2015), e revelaram a existência de pesquisas que analisaram a influência da prática de marketing no desempenho organizacional, porém, sem mencionar especificamente o ramo da contabilidade, importante ramo, foco deste estudo.

No exterior, Reid (2008) apontou que os estudos sobre práticas contemporâneas de marketing no contexto de serviços profissionais são ainda reduzidos. Sweeney, Soutar e McColl-Kennedy (2011) apontaram, também, que há necessidade de analisar outros aspectos de marketing nas organizações de serviços profissionais, como a prática de avaliação de desempenho e de relacionamento com clientes. A maioria das organizações de serviços enfrenta concorrência acirrada e precisa descobrir novas formas de obter vantagens competitivas (LOVELOCK; WIRTZ, 2007). Já no Brasil, Peleias et al. (2007) apontavam a carência de pesquisas sobre a marketing no setor de Contabilidade, situação que ainda perdura até hoje. De maneira mais ampla, organizações de serviços apresentam limitações e deficiências na prática de marketing (TARGINO; URDAN; CHAUVEL, 2013; COSTA; TURQUIELLO, 2015). Com mercados mais competitivos e clientes mais informados (e exigentes), essas organizações necessitam melhor atentar ao mercado e à concorrência, oferecer serviços de melhor qualidade e investir no relacionamento de longo prazo com clientes (COSTA; TURQUIELLO, 2015).

Assim, considerando a relevância do tema, oportunidade de ampliar pesquisas neste segmento e a importância do setor de serviços no Brasil e em Santa Catarina, decidiu-se pela realização do presente estudo com a seguinte pergunta de pesquisa: Quais são as práticas contemporâneas de marketing das empresas de Contabilidade, segundo as dimensões da perspectiva relacional proposta por Coviello, Brodie e Munro (1997) e Coviello, Milley e Marcolin (2001)? Como objetivo, o presente estudo visa analisar as práticas contemporâneas de marketing de empresas de Contabilidade localizadas no Estado de Santa Catarina, segundo as dimensões da perspectiva relacional proposta no modelo de Coviello, Brodie e Munro (1997) e Coviello, Milley e Marcolin (2001).

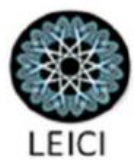




\section{Fundamentação Teórica}

Esta seção destina-se a apresentar os conceitos, origem e definições de práticas contemporâneas de marketing e resultados de estudos já realizados sobre o tema em diferentes setores e especificamente, no ramo de Contabilidade.

\subsection{Práticas Contemporâneas de Marketing}

Encontra-se na teoria de marketing a corrente de estudos sobre Práticas Contemporâneas de Marketing - Contemporary Marketing Practices (CMP). Segundo a definição de O'Dwyer, Gilmore e Carson (2009) e Sacramento e Teixeira (2014), a CMP estuda as práticas de marketing, em particular, os aspectos da gestão do relacionamento com clientes, marketing em rede, inovação em marketing, marketing digital e marketing centrado no ser humano. As pesquisas lideradas por Brodie et al. (2007) visaram ampliar o entendimento sobre as formas de relacionamento entre empresas e mercado, bem como examinar a relevância das práticas de marketing em diferentes organizações (BRODIE; COVIELLO; WINKLHOFER, 2008).

Segundo Rocha e Luce (2006), o relacionamento com clientes é a essência do marketing contemporâneo e tem suas origens na preocupação da empresa com a satisfação do consumidor. As práticas contemporâneas de marketing são utilizadas para valorizar e estabelecer relacionamentos duradouros com clientes, de modo a possibilitar o atendimento dos objetivos estratégicos da organização (KOTLER; KELLER, 2013). Como apontado por Reid (2008), há diversas pesquisas já realizadas sobre práticas de marketing contemporâneo no setor de serviços profissionais e o modelo conceitual desenvolvido por Coviello, Brodie e Munro (1997), e reformulado por Coviello, Milley e Marcolin (2001), tem sido bastante citado. O Quadro 1 apresenta o modelo proposto pelos autores sobre práticas contemporâneas de marketing. $\mathrm{O}$ modelo entende que o paradigma tradicional de marketing (foco nas transações) e o paradigma contemporâneo (foco no relacionamento) devem coexistir, e que as empresas atendem ao mercado de maneira diferente, variando conforme as condições e natureza do negócio (COVIELLO; MILLEY; MARCOLIN, 2001).

De acordo com Coviello, Brodie e Munro (1997), as práticas de marketing variam em função do nível de interação da empresa com os clientes, incluindo contato distante e impessoal com consumidores passivos (transactional marketing) até desenvolvimento de contatos com proximidade, de maneira contínua e individualizada (relationship marketing). Por conseguinte, acredita-se que nas empresas de serviços, essa abordagem do marketing encontra melhor campo (contexto) para se desenvolver, pois nele o contato interpessoal é mais forte e frequente (PIZZINATTO; FARAH, 2012). 


\section{Quadro 1 - Dimensões do marketing contemporâneo na perspectiva relacional.}

\begin{tabular}{|c|c|c|c|c|c|}
\hline & Aspectos & Marketing de Banco de Dados & Marketing Digital & Marketing Interativo & Marketing de Rede \\
\hline \multirow{5}{*}{ 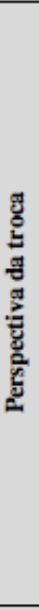 } & Objetivo da troca & $\begin{array}{l}\text { Informação e transação } \\
\text { econômica }\end{array}$ & $\begin{array}{l}\text { Diálogo gerador de } \\
\text { informaçốs entre vendedor e } \\
\text { muitos consumidores } \\
\text { identificados }\end{array}$ & $\begin{array}{l}\text { Relaçôes interpessoais entre } \\
\text { comprador e vendedor }\end{array}$ & $\begin{array}{l}\text { Obter relacionamentos com } \\
\text { outras empresas/organizaçōes }\end{array}$ \\
\hline & $\begin{array}{l}\text { Natureza da } \\
\text { comunicação }\end{array}$ & $\begin{array}{l}\text { Da empresa para segmentos de } \\
\text { mercado ou individuos-alvo }\end{array}$ & $\begin{array}{l}\text { Utilização de tecnologias para } \\
\text { se comunicar com ou entre } \\
\text { grupos e indivíduos }\end{array}$ & $\begin{array}{l}\text { Individuos com individuos, } \\
\text { nas diferentes unidades/áreas } \\
\text { da organização }\end{array}$ & $\begin{array}{l}\text { Empresa para empresa } \\
\text { (envolvendo individuos) }\end{array}$ \\
\hline & Tipo de contato & Personalizado (mas a distância) & Interativo (pela tecnologia) & $\begin{array}{l}\text { Face-a-face, interpessoal e } \\
\text { próximo, baseado no } \\
\text { compromisso, confiança e } \\
\text { cooperação }\end{array}$ & $\begin{array}{l}\text { Impessoal e interpessoal } \\
\text { (pessoal ou a distância) }\end{array}$ \\
\hline & Duraçẫo & Ocasional e ao longo do tempo & $\begin{array}{l}\text { Contínuo e com } \\
\text { interatividade on-line }\end{array}$ & $\begin{array}{l}\text { Contínuo e adaptado } \\
\text { mutuamente, de curto ou } \\
\text { longo prazo }\end{array}$ & $\begin{array}{l}\text { Contínuo, estável e dinâmico, } \\
\text { podendo ser de curto ou } \\
\text { longo prazo }\end{array}$ \\
\hline & Formalidade & $\begin{array}{l}\text { Formal (personalizado pela } \\
\text { tecnologia) }\end{array}$ & $\begin{array}{l}\text { Formal (customizado e/ou } \\
\text { personalizado pela tecnologia } \\
\text { interativa) }\end{array}$ & Formal e informal & Formal e informal \\
\hline \multirow{4}{*}{ 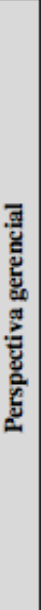 } & Intençẩo gerencial & $\begin{array}{l}\text { Retenção de clientes, visando a } \\
\text { satisfação dos clientes, aumento } \\
\text { da lucratividade e lealdade, e } \\
\text { redução do risco do cliente) }\end{array}$ & $\begin{array}{l}\text { Criação de diálogos pela } \\
\text { tecnologia da informação }\end{array}$ & $\begin{array}{l}\text { Estabelecer e desenvolver } \\
\text { interaçốes com clientes, } \\
\text { facilitando o relacionamento } \\
\text { cooperativo e beneficios } \\
\text { mútuos }\end{array}$ & $\begin{array}{l}\text { Interação coordenada entre } \\
\text { vendedores, compradores e } \\
\text { outros profissionais de } \\
\text { diferentes empresas, visando } \\
\text { obter beneficios mútuos) }\end{array}$ \\
\hline & Foco gerencial & $\begin{array}{l}\text { Produto/marca e clientes (em } \\
\text { um mercado-alvo) }\end{array}$ & $\begin{array}{l}\text { Gestão de relacionamentos } \\
\text { entre a empresa e muitos } \\
\text { indivíduos pela tecnologia da } \\
\text { informação }\end{array}$ & Relaçôes entre individuos & $\begin{array}{l}\text { Relacionamento em rede com } \\
\text { outras empresas ou } \\
\text { organizaçôes }\end{array}$ \\
\hline & $\begin{array}{l}\text { Investimento } \\
\text { gerencial }\end{array}$ & $\begin{array}{l}\text { Ativos de marketing interno } \\
\text { (ênfase nas capacidades de } \\
\text { comunicação, informação e } \\
\text { tecnologia) }\end{array}$ & $\begin{array}{l}\text { Ativos operacionais internos } \\
\text { (TI, website, logistica); } \\
\text { Integraçắo de sistemas } \\
\text { funcionais }\end{array}$ & $\begin{array}{l}\text { Ativos do mercado externo } \\
\text { (foco no estabelecimento e } \\
\text { desenvolvimento de } \\
\text { relacionamentos com outros } \\
\text { individuos) }\end{array}$ & $\begin{array}{l}\text { Ativos do mercado externo } \\
\text { (foco no desenvolvimento da } \\
\text { posiçăo da empresa em redes } \\
\text { de relacionamento) }\end{array}$ \\
\hline & Nivel gerencial & $\begin{array}{l}\text { Especialistas em marketing (ex: } \\
\text { gestor de serviços ao cliente e } \\
\text { gestor de contas de clientes) }\end{array}$ & $\begin{array}{l}\text { Especialistas em marketing } \\
\text { com especialistas em } \\
\text { tecnologia e gerentes seniores }\end{array}$ & $\begin{array}{l}\text { Funcionários e gerentes (de } \\
\text { todas as áreas/funções e } \\
\text { niveis da empresa) }\end{array}$ & Gerente sênior \\
\hline
\end{tabular}

Fonte: Coviello, Brodie e Munro (1997) e Coviello, Milley e Marcolin (2001).

Estudo de Ensslin et al. (2015) e Sarquis et al. (2016) revelaram que dentre os temas mais abordados em estudos internacionais de marketing para pequenas empresas estão as Práticas Contemporâneas de Marketing. O’Dwyer, Gilmore e Carson (2009), Cronin-Gilmore (2012) e Sacramento e Teixera (2014) apontam que práticas contemporâneas incluem inovação em produtos e serviços, canais (multicanais e ominichannel), formas criativas de promover produtos e marcas, marketing de rede, gestão do relacionamento com clientes, inovação em processos de marketing, marketing de experiências, marketing sensorial, marketing digital.

Recentemente, Cittadin et al. (2017) evidenciaram que pequenas empresas de vestuário de Santa Catarina se utilizam de maneira intensa e consciente de estratégias contemporâneas de marketing, dentre elas o marketing de relacionamento, marketing de rede e marketing digital, temas estes também abordados na presente pesquisa. No tocante ao marketing de relacionamento o estudo corroborou com pesquisa anterior de Coviello, Winklhofer e Hamilton 
(2006), a qual postulou que tais práticas estão presentes em pequenas empresas de serviços e podem influenciar diretamente o desempenho de vendas.

Com relação ao uso de marketing digital, a pesquisa de Cittadin et al. (2017) identificou intenso uso de redes sociais, principalmente o uso de Facebook, Instagran e Whatsapp. Tais ferramentas são utilizadas por pequenas empresas de maneira criativa e com baixo custo para promoção de produtos e interação com clientes. O estudo mostrou avanços a pesquisa de Gilmore, Gallagher e Henry (2007) e de Taiminen e Karjaluoto (2015) os quais apontavam que as pequenas empresas ainda não acompanhavam o desenvolvimento digital e não aproveitavam de forma adequada esta oportunidade. O estudo ainda reforçou resultados de Sacramento e Teixeira (2014), os quais pesquisaram sobre inovação em pequenas empresas de serviço de hospedagem. Para eles, a principal inovação encontrada foi justamente o uso de redes sociais em pequenas empresas, como canal de divulgação da marca/serviços e de comunicação direta.

Cittadin et al. (2017) mostraram que pequenas empresas adquirem vantagem competitiva em seus negócios através de sua network de marketing, ou seja, sua facilidade em se comunicar e relacionar com as redes de stakeholders. Trabalhando em conjunto, os pequenos empresários têm acesso a informações privilegiadas, consultorias de órgão especializados, participações de eventos e feiras. Estes resultados corroboraram pesquisas anteriores de Jones, Suoranta e Rowley (2013) destacando que esta prática é relacionada diretamente a capacidade de interação dos sócio-proprietários com o mercado.

Focando no setor de serviços, estudo de Reid (2008) revelou que pequenas organizações enfrentam dificuldades de mercado, como: ambiente mais competitivo, oferta de serviços equivalentes, surgimento de novos competidores, carência de mão de obra qualificada e desafios provenientes da popularização da internet. Além disso, o autor afirma que os consumidores desses serviços estão se tornando mais exigentes e menos leais à marca, e as organizações necessitam de novas alternativas para vender seus serviços e desenvolver relacionamentos com clientes. Na mesma linha, o estudo de Coviello et al. (2002), envolvendo 308 empresas de diversos ramos, constatou que as organizações de serviços profissionais operam mais na perspectiva relacional do que as empresas de bens manufaturados, mas que 95\% dos gestores definem suas empresas como tradicionais (ou seja, orientadas principalmente para transação) com relação à prática de marketing.

Nas empresas de serviços profissionais, o processo de gestão do relacionamento com clientes é fundamental, e pode contribuir para a vantagem competitiva (REID, 2008). Neste sentido, o estudo apontou que as empresas de serviços profissionais necessitam competir agressivamente para conquistar negócios/clientes, investem mais em estratégias de marketing contemporâneo e fazem avaliação do desempenho de marketing, utilizando métricas de desempenho que variam conforme as características da organização. Referindo ainda a vantagem competitiva, estudo de Rech (2009) propôs um modelo conceitual para análise competitiva em micro e pequenas empresas. Neste modelo, os autores colocam o marketing de

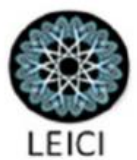


relacionamento como base fundamental para a criação de valor e competitividade em empresas de micro e pequeno porte. Ainda, vale ressaltar que empresas de Contabilidade utilizam poucas estratégias, práticas e ferramentas de marketing como observa-se a seguir.

\subsection{Resultados de estudos sobre marketing no setor de Contabilidade}

Estudo de Hiroshi (1998) já evidenciava problemas de comunicação dos escritórios de contabilidade com seu público, principalmente pela falta de conhecimento que os contadores da época tinham em relação a gestão de marketing. Já Paleias, Hernandes, Garcia e Silva (2007) ao abordar marketing contábil para melhorar a imagem de escritórios de Contabilidade, revelaram que os contadores ainda utilizavam ferramentas de marketing de forma intuitiva, (feeling) e básica. Os autores sugerem ainda que poderia haver um estreitamento de relação entre sócios de escritórios contábeis e clientes, no sentido de entender melhor suas necessidades e poder oferecer um serviço personalizado. Já o estudo de Feldman Barr e McNeilly (2003) no ramo de Contabilidade, revelou que a falta de recursos (financeiros, pessoal) dificulta a concepção e implementação de planejamentos de marketing, e que nas empresas pesquisadas, os investimentos em marketing eram mais em atividades de natureza tático-operacional.

A pesquisa de Peleias et al. (2007) sobre a utilizaram de ferramentas de marketing em escritórios de contabilidade do estado de São Paulo revelou que o uso de instrumentos de marketing ainda é intuitivo (sem planejamento) e embrionário no setor. O estudo apontou ainda que os gestores não conhecem de forma mais explícita as ferramentas de marketing; os gestores demonstraram preocupação sobre a importância de ter profissionais qualificados no setor de serviços, a qualidade ainda não é percebida pelos gestores como um instrumento de marketing. Por fim, a maioria dos escritórios de contabilidade pertencentes ao estudo oferecem "cardápio tradicional" (serviços padrões) aos clientes, prática onde poderiam estreitar o relacionamento ofertando serviços personalizados e/ou customizados.

Estudo de Dias Filho e Santos (2013) objetivou discutir a importância do marketing de serviços e verificar a percepção dos empreendedores contábeis em relação a utilidade das ferramentas de marketing para os escritórios de contabilidade. Seus resultados indicaram que a maioria considera as estratégias de marketing como importantes para o crescimento de seu negócio. No entanto, a minoria admitiu usar esta prática de forma constante. Foi verificado ainda que quando ferramentas de marketing são usadas por escritórios de contabilidade, o intuito principal é captar clientes e em segundo lugar fideliza. Para fidelizar os sócios de escritórios pesquisados afirmaram se utilizar de brindes promocionais e para captar se utilizam de websites, ou seja, de estratégias de marketing digital.

Por fim, Menelec e Jones (2015) analisaram como as pequenas organizações de serviços profissionais (incluindo empresas de Contabilidade) do Reino Unido utilizam redes de relacionamento como estratégias de marketing. Os resultados apontaram que as empresas
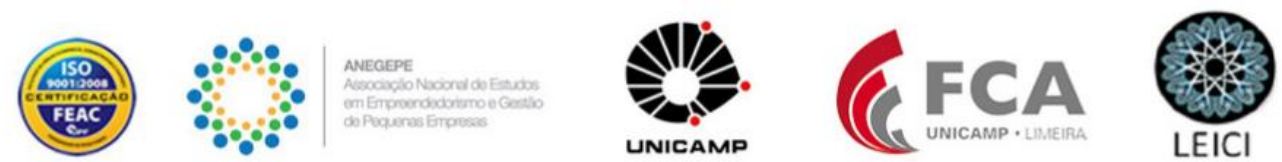
pesquisadas investem mais em rede social, incluindo relações com comunidade, outras empresas parceiras e órgãos de estado; que as estratégias de marketing de relacionamento contribuem para melhorar o desempenho e a competitividade de mercado da organização.

\section{Aspectos Metodológicos}

Trata-se de estudo quantitativo, descritivo, na forma de levantamento de campo e de corte transversal (MALHOTRA, 2012). A população do estudo são empresas de contabilidade que atuam de maneira formal (registrada), de diferentes tamanhos/portes de empresas e localizadas no Estado de Santa Catarina. Para identificar a população do estudo, uma listagem de empresas de contabilidade foi elaborada a partir de informações fornecidas pela empresa DataWash e pelo Conselho Regional de Contabilidade do estado de Santa Catarina (CRC-SC).

A coleta de dados envolveu a aplicação de questionário auto administrado, disponibilizado na plataforma Google Docs e apoiado por e-mail convite personalizado, enviado ao universo das empresas de contabilidade do Estado de Santa Catarina identificadas. O CRC-SC também encaminhou o questionário via e-mail a todos escritórios de contabilidade registrados. O estudo teve uma população estimada de 1290 empresas de Contabilidade e uma amostra de 58, obtendo 4,5\% da taxa de resposta. O questionário de pesquisa foi elaborado com base nos trabalhos de Coviello, Brodie e Munro (1997), Coviello, Milley e Marcolin (2001), Reid (2008) e Sweeney, Soutar e McColl- Kennedy (2011). As perguntas sobre práticas de marketing e desempenho de marketing foram estruturadas em formato de escala tipo Likert de 5 pontos. As demais perguntas foram estruturadas em escalas nominal ou ordinal.

$\mathrm{Na}$ análise dos dados, os questionários recebidos foram verificados para confirmar o adequado preenchimento e validade. Questionários não considerados válidos foram eliminados. Os dados primários coletados foram tabulados e analisados por meio dos softwares Microsoft Office Excel - Versão 2016 e SPSS (Statistical Package for the Social Sciences) - Versão 24, conforme a escala de mensuração utilizada nas diferentes questões do questionário. Foi feito a análise da consistência interna do questionário, utilizando a técnica estatística Alpha de Cronbach (CRONBACH, 1951). Os resultados do Alfa de Cronbach $(\alpha)$ sugerem que o instrumento de pesquisa aplicado tem confiabilidade muito alta, com base no coeficiente total da escala $(\alpha=0,968)$. Nas dimensões marketing digital $(\alpha=0,906)$ e marketing de rede $(\alpha=0,928)$, a confiabilidade da escala é muito alta; nas dimensões marketing de banco de dados $(\alpha=0,883)$, marketing interativo $(\alpha=0,884)$, e métricas de desempenho de marketing $(\alpha=0,869)$. Posteriormente, a análise da normalidade dos dados foi verificada e utilizou-se o teste de Kolmogorov-Smirnov, por variável de pesquisa mensurada. Os resultados do teste apresentam Sig/P-value 0,000 , ou seja, os dados analisados se originam de uma distribuição considerada normal. Utilizou-se técnicas de estatística descritiva para analisar os demais dados da pesquisa.

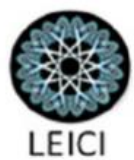




\section{Apresentação e Análise dos Resultados}

A Tabela 1 apresenta o percentual de investimento em marketing realizado pelas empresas de Contabilidade. A maioria das empresas declararam investir no máximo 3\% do faturamento; 19,3\% das empresas declararam investir de 3,1 a 6\%; e 10,52\% das empresas declararam investir mais do que $6,1 \%$ do faturamento. Já sobre o perfil das empresas participantes do estudo (total de 58), 52 são empresas de micro e pequeno porte (até 49 funcionários, de acordo com o Sebrae), 37 empresas possuem mais de 8 anos de atuação no mercado e $91,4 \%$ das empresas afirmaram atender a mercado B2B (business to business).

Tabela 1 - Percentual de investimento em marketing $(n=58)$.

\begin{tabular}{|l|c|c|}
\multirow{2}{*}{$\begin{array}{c}\text { Percentual de investimento em } \\
\text { marketing em 2016 }\end{array}$} & \multicolumn{2}{c}{ Contabilidade } \\
\cline { 2 - 3 } & Qtde. & $\%$ \\
\hline Até 1\% & 19 & 33,33 \\
\hline De 1,1 a 3\% & 21 & 36,84 \\
\hline De 3,1 a 6\% & 11 & 19,3 \\
\hline De 6,1 a 9\% & 1 & 1,75 \\
\hline Acima de 9\% & 5 & 8,77 \\
\hline
\end{tabular}

Fonte: Elaborado pelos autores (2018).

A Tabela 2 apresenta os resultados de prática de marketing de banco de dados pelas empresas pertencentes a amostra do estudo.

Tabela 2 - Resultados de prática de marketing de banco de dados $(\mathbf{n}=58)$.

\begin{tabular}{l|c|c}
\multicolumn{1}{c}{ Variáveis - Marketing de banco de dados } & \multicolumn{2}{c}{ Contabilidade } \\
\cline { 2 - 3 } & $\mathbf{\%}$ & $\mathbf{x}$ \\
\hline Obtém dados de clientes via contatos & 42,9 & 3,3 \\
\hline Comunicação dirigida segmentos & 37,0 & 3,0 \\
\hline Comunicação direta personalizada & 56,4 & 3,7 \\
\hline Clientes esperam contato personalizado & 67,9 & 3,9 \\
\hline Atende de modo formal e personalizado & 58,2 & 3,7 \\
\hline Marketing foca retenção clientes & 35,4 & 3,2 \\
\hline Planejamento focaliza segmentos & 29,2 & 2,8 \\
\hline Investe tecnologia na comunicação com clientes & 31,3 & 2,8 \\
\hline Responsável por marketing é especializado & 27,5 & 2,3 \\
\hline
\end{tabular}

Fonte: Elaborado pelos autores (2018). 
Sobre a prática de marketing de banco de dados evidenciadas na Tabela 2, a maioria das empresas pesquisadas investe somente em: atendimento personalizado com clientes $(67,9 \%)$, atende aos clientes de modo formal e personalizado $(58,2 \%)$ e faz comunicação direta e personalizada $(56,4 \%)$. As práticas de marketing de banco de dados menos utilizadas são: obtêm dados sobre clientes via contatos/negociações no dia-a-dia (42,9\%), faz comunicação dirigida a segmentos específicos $(37 \%)$, atividades de marketing focalizam a retenção dos clientes $(35,4 \%)$, investe em TI para se comunicar com clientes $(31,3 \%)$, planejamento de marketing foca os clientes $(29,2 \%)$ e responsável por marketing é profissional especializado $(27,5 \%)$.

Tabela 3 - Resultados de prática de marketing digital $(\mathbf{n = 5 8})$.

\begin{tabular}{l|c|c}
\multicolumn{1}{c}{ Variáveis - Marketing digital } & \multicolumn{2}{c}{ Contabilidade } \\
\cline { 2 - 3 } & $\mathbf{\%}$ & $\mathbf{x}$ \\
\hline Obtém dados que melhoram o diálogo com compradores & 29,8 & 2,8 \\
\hline Internet apoia a comunicação com clientes & 64,9 & 3,8 \\
\hline Faz contatos interativos via Internet & 66,1 & 3,8 \\
\hline Clientes desejam interação online & 45,5 & 3,4 \\
\hline Faz atendimento personalizado via tecnologia & 49,1 & 3,5 \\
\hline Atividades de marketing que promovem diálogos pela internet & 27,1 & 2,8 \\
\hline Planejamento foca relacionamento via internet & 27,1 & 2,7 \\
\hline Investe na interação pela internet & 40,0 & 3,1 \\
\hline Responsável por marketing é especializado em tecnologia & 26,2 & 2,3 \\
\hline
\end{tabular}

Fonte: Elaborado pelos autores (2018).

Sobre as práticas de marketing digital apresentadas na Tabela 3, a maioria das empresas pesquisadas utilizam apenas as seguintes práticas: contatos interativos com clientes pela Internet $(66,1 \%)$ e uso da internet como apoio na comunicação com clientes $(64,9 \%)$. As práticas de marketing digital menos utilizadas são: atendimento personalizado via tecnologia $(49,1 \%)$; interação online com clientes $(45,5 \%)$; investe na interação com clientes pela internet (40\%); obtêm dados que melhoram o diálogo entre funcionários e clientes pela Internet (29,8\%); atividades de marketing promovem diálogo pela Internet $(27,1 \%)$; planejamento de marketing focaliza relacionamento com clientes pela Internet $(27,1 \%)$ e responsável por marketing é profissional especializado e trabalha com tecnologia $(26,2 \%)$.

Tabela 4 - Resultados de prática de marketing interativo $(n=58)$. 


\begin{tabular}{l|c|c}
\multicolumn{1}{c}{ Variáveis - Marketing interativo } & \multicolumn{2}{c}{ Contabilidade } \\
\cline { 2 - 3 } & $\mathbf{\%}$ & $\mathbf{x}$ \\
\hline Desenvolve relacionamento com clientes específicos & 64,0 & 3,6 \\
\hline Faz comunicação de marketing via funcionários & 33,3 & 3,1 \\
\hline Faz contato interpessoal com clientes & 47,2 & 3,3 \\
\hline Clientes desejam interação individualizada & 71,9 & 4,1 \\
\hline Atende de modo informal e social & 54,5 & 3,7 \\
\hline Marketing promove interação cooperativa com clientes & 19,1 & 2,8 \\
\hline Planejamento foca a interação com clientes/entidades específicos & 14,9 & 2,6 \\
\hline Investe na interação pessoal com clientes & 21,3 & 2,6 \\
\hline Responsável por marketing é gestores funcionais & 43,8 & 3,2 \\
\hline
\end{tabular}

Fonte: Elaborado pelos autores (2018).

Em relação as práticas de marketing interativo demonstradas na Tabela 4, os resultados indicam que a maioria das empresas pesquisadas utilizam as seguintes práticas: atendimento de maneira pessoal e individualizada (71,9\%); desenvolve relacionamento de longo prazo com clientes específicos $(64 \%)$ e atendimento de maneira informal e social $(54,5 \%)$. As práticas de marketing interativo menos utilizadas são: contato interpessoal com clientes (47,2\%); responsável por marketing responde também por outras atividades/funções $(43,8 \%)$; faz comunicação de marketing por meio de funcionários (33,3\%); investe na interação pessoal com clientes $(21,3 \%)$; atividades de marketing promovem relacionamento cooperativo com clientes $(19,1 \%)$ e planejamento de marketing focaliza a interação com clientes e pessoas de organizações parceiras $(14,9 \%)$.

Tabela 5 - Resultados de prática de marketing de rede $(n=58)$.

\begin{tabular}{l|c|c}
\multicolumn{1}{c}{ Variáveis - Marketing de rede } & \multicolumn{2}{c}{ Contabilidade } \\
\cline { 2 - 3 } & \% & $\mathbf{x}$ \\
\hline Desenvolve relacionamento intenso com outras organizações & 31,4 & 3,0 \\
\hline Faz comunicação de marketing em rede via gestores & 22,9 & 2,7 \\
\hline Investe em contatos interpessoais com clientes e outras organizações & 33,3 & 3,1 \\
\hline Clientes desejam ter contatos via rede & 44,2 & 3,4 \\
\hline Tem relacionamentos sociais com clientes e outras organizações & 34,5 & 3,2 \\
\hline Ações de marketing coordenam funcionários, clientes e entidades & 20,8 & 2,6 \\
\hline Planejamento foca o desenvolvimento de redes & 21,7 & 2,6 \\
\hline Recursos de marketing no desenvolvimento de redes & 21,7 & 2,6 \\
\hline Responsável por marketing é proprietário e/ou dirigente & 42,9 & 3,1 \\
\hline
\end{tabular}

Fonte: Elaborado pelos autores (2018). 
Por fim, sobre as práticas de marketing de rede apresentadas na Tabela 5, os resultados indicam que nenhuma das práticas mensuradas são utilizadas pela maioria das empresas pesquisadas. As práticas de marketing de rede utilizadas por menos de $50 \%$ das empresas pesquisadas são: atende a clientes que desejam ter contatos via rede de relacionamento $(44,2 \%)$; responsável por marketing é proprietário ou principal executivo da empresa $(42,9 \%)$; tem relacionamentos sociais com clientes e outras organizações do mercado $(34,5 \%)$; investe em contatos interpessoais com clientes e outras organizações do mercado (33,3\%); tem relacionamento intenso com outras organizações do mercado $(31,4 \%)$; faz comunicação de marketing por meio de gestores que atuam em redes de relacionamento $(22,9 \%)$; planejamento de marketing focaliza a construção de redes de relacionamento $(21,7 \%)$; tem recursos de marketing investidos no desenvolvimento de redes de relacionamento $(21,7 \%)$; tem ações de marketing projetadas para coordenara interação entre funcionários, clientes e outras organizações do mercado $(20,8 \%)$.

Tabela 6 - Resultados das métricas de desempenho de marketing $(n=58)$.

\begin{tabular}{l|c|c}
\multirow{2}{*}{\multicolumn{1}{c|}{ Variáveis }} & \multicolumn{2}{c}{ Contabilidade } \\
\cline { 2 - 3 } & \% & $\mathbf{x}$ \\
\hline Crescimento_venda & 46 & 3,3 \\
\hline Margem_lucro & 49 & 3,5 \\
\hline ROI & 32,7 & 3,1 \\
\hline Participação_mercado & 23,9 & 2,7 \\
\hline Conquista_clientes & 53,7 & 3,6 \\
\hline Retenção_clientes & 60,4 & 3,8 \\
\hline Satisfação_clientes & 67,3 & 3,9 \\
\hline
\end{tabular}

Fonte: Elaborado pelos autores (2018).

Os resultados apresentados na Tabela 6 apontaram que as empresas de contabilidade utilizam com mais frequência a satisfação de clientes, retenção de clientes e conquista de novos clientes como métrica de desempenho de marketing. A métrica participação de mercado é menos utilizada por empresas deste segmento para analisar o desempenho de marketing.

\subsection{Discussão dos resultados}

Como ocorreu no estudo de Reid (2008) e de Sweeney, Soutar e McColl Kennedy (2011) na Austrália, a participação das empresas de contabilidade em ações de marketing ainda deve ser estimulada. Os gestores de empresas deste segmento ainda não percebem a importância de estudar, entender e atender o mercado consumidor de maneira diferente, buscando por meio de estratégias de marketing obter vantagem competitiva sustentável. 
Os resultados mostram, também, que a maioria das empresas de contabilidade pertencentes ao estudo tem mais de 10 anos de existência, como ocorreu em Reid (2008) e no estudo de Sweeney, Soutar e McColl Kennedy (2011) na Austrália, onde mais da metade das empresas de serviços profissionais pesquisadas tinham mais de 10 anos de mercado. Em estudo realizado por Targino, Urdan e Chauvel (2013) no Brasil, 60\% das empresas de serviços profissionais pesquisadas atuam no mercado B2B; em Reid (2008) na Austrália, 67,4\% das empresas participantes atendem somente a mercados B2B; e no presente estudo, 91,4\% das empresas afirmaram atender a mercados $\mathrm{B} 2 \mathrm{~B}$.

Ao analisar os dados da pesquisa, percebe-se que as empresas de Contabilidade do estado de SC não utilizam com tanta frequência e diversidade, as estratégias e práticas contemporâneas de marketing. Talvez, como apontado por Reid (2008), as empresas de pequeno porte tenham mais dificuldade de utilizar práticas de marketing, em decorrência da pouca disponibilidade de recursos tecnológicos e da carência de pessoal especializado. Brodie et al. (2007) afirmaram, e mais recentemente Nobre e Silva (2014), que o marketing digital (principalmente o Facebook) tem papel relevante e pode contribuir para melhorar o relacionamento com stakeholders da empresa. Cittadin et al. (2017) também evidenciou isto em estudos publicado recentemente.

As práticas de marketing de rede também são utilizadas com pouca frequência pelas empresas de contabilidade em Santa Catarina. Rogan e Mors (2016) já apontaram que práticas de marketing de rede tendem a melhorar o desempenho da empresa em termos de novos negócios e conhecimento de mercado. Ao contrário, estudo de Cittadin et al. (2017) verificou que empresas de confecção (produtos) se utilizam fortemente deste tipo de estratégia. Cabe portanto, um questionário aos gestores do motivo de não utilização.

Em relação as métricas de desempenho de marketing, as mais utilizadas são satisfação de clientes, retenção de clientes e conquista de clientes, contrariando os achados de Reid (2008) na Austrália, onde tais empresas utilizaram pouco métricas baseadas no cliente (ex: aquisição, retenção e satisfação de clientes). Porém, estes resultados corroboram, no entanto, com os achados de Sweeney, Soutar e McColl-Kennedy (2011) sobre micro e pequenas empresas na Austrália, que revelaram a utilização de métricas de marketing, como lealdade do cliente, satisfação do cliente e referências do cliente.

\section{Considerações Finais}

O estudo buscou analisar as práticas contemporâneas de marketing de empresas de Contabilidade localizadas no Estado de Santa Catarina, segundo as dimensões da perspectiva relacional proposta no modelo de Coviello, Brodie e Munro (1997) e Coviello, Milley e Marcolin (2001). Especificamente, identificar as métricas de desempenho de marketing utilizadas pelas empresas. Os objetivos propostos foram alcançados. 
O estudo apresenta contribuição teórica relevante, revelando que o modelo teórico de Coviello, Brodie e Munro (1997) e Coviello, Milley e Marcolin (2001), é adequado para analisar as práticas contemporâneas de marketing de empresas de serviços profissionais, no contexto da realidade brasileira, especificamente, em empresas de Contabilidade. Ainda, apresenta diversos dados empíricos sobre práticas contemporâneas de marketing em empresas de Contabilidade no Brasil (um contexto ainda pouco estudado). Além disso, a coleta de dados teve como fontes de informações gestores/proprietários das empresas de Contabilidade pesquisadas, enquanto os poucos estudos existentes sobre o tema contêm dados coletados na perspectiva do consumidor.

Algumas recomendações gerenciais são necessárias para as empresas que pouco utilizam práticas contemporâneas de marketing. Recomenda-se aos gestores das empresas de Contabilidade a utilização de práticas de marketing digital e marketing de rede. Como práticas de marketing digital, sugere-se que: responsável por marketing ser profissional especializado em tecnologia, atividades que promovem diálogo com clientes pela Internet, planejamento que focaliza relacionamentos pela Internet, obtenção de dados que melhorem o diálogo funcionários-clientes. E no marketing de rede, sugere-se: ações que envolvam funcionários, clientes e outras entidades do mercado, planejamento que focaliza a construção de redes de relacionamento, recursos para o desenvolvimento de redes de relacionamento e ações de comunicação de marketing via gestores que atuam em redes de relacionamento.

Desta forma, conclui-se que os estudos sobre as práticas contemporâneas de marketing precisam ocorrer em diferentes setores e ramos de atividades. O setor de serviços é o mais estudado, principalmente os ramos de serviços profissionais, incluindo instituição de ensino superior, engenharia, arquitetura, advocacia e contabilidade. Nota-se, por exemplo, uma carência de estudos nos ramos de gastronomia, hotelaria, imobiliária, organizações sem fins lucrativos, agências de publicidade, hospitais médicos, tecnologia da informação. Na mesma linha, poucos estudos foram realizados nos setores de varejo e bens de consumo (basicamente sobre alimentos). Como sugeriram Sweeney, Soutar e McColl-Kennedy (2011), novos estudos poderiam analisar a CMP nas organizações de diversos setores e ramos de atividades, buscando verificar semelhanças e diferenças frente ao desempenho de marketing, e no estudo das dimensões que mais impactam o desempenho da empresa.

Algumas limitações do estudo devem ser consideradas, no caso de utilização dos resultados. Como o método de amostragem é não probabilístico (seleção dos participantes por conveniência), os resultados não são conclusivos e não podem ser generalizados. O tamanho amostral representa cerca de $4 \%$ da população do estudo, tendo baixa participação das empresas de médio-grande porte. Com isso, o perfil da amostra do estudo pode não refletir o conjunto das empresas do setor de Contabilidade do Estado de Santa Catarina.

\section{Referências}
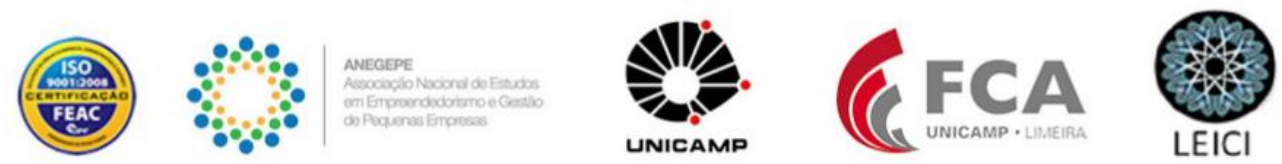
BRODIE, R. J.; WINKLHOFER, H.; COVIELLO, N. E.; JOHNSTON, W. J. Is e-marketing coming of age? An examination of the penetration of e-marketing and firm performance. Journal of Interactive Marketing, v. 21, n. 1, p. 2-21, 2007.

CITTADIN, J.; SARQUIS, A. B.; SOARES, J. C.; COHEN, E. D. Gestão de marketing na pequena empresa de confecção de vestuários. Revista Eletrônica de Administração e Turismo, v. 11, n. 6, p. 1326-1348, 2017.

COSTA, M. R.; TURQUIELLO, J. P. Um estudo no atual processo mercadológico em clínicas veterinárias do município de Dourados-MS. Revista de Ciências Gerenciais, v. 17, n. 26, p. 45-56, 2015.

COVIELLO, N. E.; BRODIE, R. J.; DANAHER, P. J.; JOHNSTON, W. J. How firms relate to their markets: an empirical examination of contemporary marketing practices. Journal of Marketing, v. 66, n. 3, p. 33-46, 2002.

COVIELLO, N. E.; BRODIE, R. J.; MUNRO, H. J. Understanding contemporary marketing: development of a classification scheme. Journal of Marketing Management, v. 13, n. 6, p. 501-522, 1997.

COVIELLO, N. E.; MILLEY, R.; MARCOLIN, B. Understanding IT-enabled interactivity in contemporary marketing. Journal of Interactive Marketing, v. 15, n. 4, p. 18-33, 2001.

COVIELLO, N. E.; WINKLHOFER, H.; HAMILTON, K. Marketing practices and performance of small service firms an examination in the tourism accommodation sector. Journal of Service Research, v. 9, n. 1, p. 38-58, 2006.

CRONBACH, L. J. Coefficient alpha and the internal structure of tests. Psychometrika, v. 16, n. 3, p. 297-334, 1951.

CRONIN-GILMORE, J. Exploring marketing strategies in small businesses. Journal of Marketing Development and Competitiveness, v. 6, n. 1, p. 96, 2012.

DIAS FILHO, F. F.; SANTOS, V. A percepção dos profissionais contábeis de Belo Horizonte sobre a utilidade do marketing de serviços para os escritórios de contabilidade. Revista Mineira de Contabilidade, v. 3, n. 51, p. 16-23, 2015.

ENSSLIN, L.; SARQUIS, A. B.; CITTADIN, J.; CHAVES, L. Evidenciação do Estado da Arte sobre Marketing para Pequenas Empresas: Levantamento e Análise do Período 20032013. Revista da Micro e Pequena Empresa, v. 9, n. 3, p. 2-21, 2015.

FELDMAN BARR, T.; MCNEILLY, K. M. Marketing: Is it still "just advertising”? The experiences of accounting firms as a guide for other professional service firms. Journal of Services Marketing, v. 17, n. 7, p. 713-729, 2003. 
GILMORE, A.; GALLAGHER, D.; HENRY, S. E-marketing and SMEs: operational lessons for the future. European Business Review, v. 19, n. 3, p. 234-247, 2007.

HIROSHI, S. Um plano de marketing para a contabilidade. Caderno de Estudos, n. 17, p. 01-16, 1998.

IBGE - Instituto Brasileiro de Geografia e Estatística. Pesquisa Anual de Serviços, 2014. http://brasilemsintese.ibge.gov.br/servicos.html

JONES, R.; SUORANTA, M.; ROWLEY, J. Strategic network marketing in technology SMEs. Journal of Marketing Management, v. 29, n. 5-6, p. 671-697, 2013.

KOTLER, P.; KELLER, K.L. Administração de Marketing. São Paulo: Pearson Prentice Hall, 2013.

LOVELOCK, C.; WRIGHT, L. Serviços: marketing e gestão. São Paulo: Saraiva, 2007.

MALHOTRA, N. K. Pesquisa de marketing: uma orientação aplicada. Porto Alegre: Bookman, 2012.

MENELEC, V.; JONES, B. Networks and marketing in small professional service businesses. Journal of Research in Marketing and Entrepreneurship, v. 17, n. 2, p. 193- 211, 2015.

NOBRE, H.; SILVA, D. Social network marketing strategy and SME strategy benefits. Journal of Transnational Management, v. 19, n. 2, p. 138-151, 2014.

O'DWYER, M.; GILMORE, A.; CARSON, D. Innovative marketing in SMEs. European Journal of Marketing, v. 43, n. 1, p. 46-61, 2009.

PATTERSON, P. Retrospective: tracking the impact of communications effectiveness on client satisfaction, trust and loyalty in professional services. Journal of Services Marketing, v. 30, n. 5, p.1-13, 2016.

PELEIAS, I. R.; HERNANDES, D. C. R.; GARCIA, M. N.; SILVA, D. Marketing contábil nos escritórios de contabilidade do Estado de São Paulo. Revista Brasileira de Gestão de Negócios, v. 9, n. 23, 2007.

PEREIRA, M. Z.; BASTOS, S. Q. A.; PEROBELLI, F. S. Análise sistêmica do setor de serviços no Brasil para o ano de 2005. Revista Pesquisa e Planejamento Econômico, v. 43, n.1, p. 162-201, 2013.

PIZZINATTO, N. K.; FARAH, O. E. Pesquisa pura e aplicada para marketing: processos e aplicações. São Paulo: Atlas, 2012. 
REID, M. Contemporary marketing in professional services. Journal of Services Marketing, v. 22 , n. 5 , p. 374-384, 2008.

RECH, S.R. Modelo Conceitual de Análise Competitiva em Micro e Pequenas Empresas do Setor de Confecções. UNOPAR Cient., Ciênc. Juríd. Empres., Londrina, v. 10, n. 1, p. 512, Mar. 2009.

ROCHA, A.; LUCE, F. B. Relacionamentos entre compradores e vendedores: origens e perspectivas no marketing de relacionamento. Revista de Administração de Empresas (ERA), v. 46, n. 3, p. 87-93, 2006.

ROGAN, M.; MORS, M. L. Managerial Networks and Exploration in a Professional Service Firm. Organization Studies, p. 1-25, 2016.

SACRAMENTO, P. M.; TEIXEIRA, R. M. Adoção de inovações em empresas de pequeno e médio porte: estudo de casos múltiplos em negócios hoteleiros na cidade de Aracaju. Revista Organizações em Contexto, v. 10, n. 19, p. 1-30, 2014.

SARQUIS, A. B.; CITTADIN, J.; MORAIS, A. S. A.; TONDOLO, R. D. R. P.; SANTOS, E. O Estado da Arte do Tema Marketing para Pequenas Empresas: Um estudo bibliométrico da produção científica nacional. Revista Brasileira de Gestão e Inovação, v. 3, n. 3, p. 109$134,2016$.

SEBRAE (Org.). Anuário do trabalho nos pequenos negócios em 2015. Brasília/DF, 2017.

SWEENEY, J. C.; SOUTAR, G. N.; MCCOLL-KENNEDY, J. R. The marketing practicesperformance relationship in professional service firms. Journal of Service Management, v. 22, n. 3, p. 292-316, 2011.

TAIMINEN, H. M.; KARJALUOTO, H. The usage of digital marketing channels in SMEs. Journal of Small Business and Enterprise Development, v. 22, n. 4, p. 633-651, 2015.

TARGINO, L. T.; URDAN, A. T.; CHAUVEL, M. A. As Práticas de marketing, entre transações e relacionamentos, de empresas no Brasil. Brazilian Business Review (BBR), v. 10, n. 2, p. 124-141, 2013. 